\title{
Program Pengembangan Usaha Produk Intelektual Kampus "Kantor Konsultan Bisnis, Akuntansi dan Pajak"
}

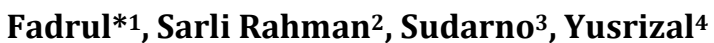 \\ 1,2,3,4 Fakultas Bisnis Institut Bisnis dan Teknologi Pelita Indonesia \\ *e-mail: fadrul@lecturer.pelitaindonesia.ac.id
}

\begin{abstract}
Every college must have a business unit that is able to seek funding apart from students. One of the universities that has a business unit is the Institut Bisnis dan Teknologi Pelita Indonesia. The business unit that is carried out is the Business, Accounting and Tax Consultant Office with services offered namely business consulting, accounting and finance and taxation. Some of the clients that have been handled by the consultant team are Raso Stiujuah Restaurant and BUMDes Sialang Kubang. The method used is that the consultant team looks for the root of every problem faced by the client, then provides the best solution for the client. For Raso Situjuah Restaurant, to survive the changing business world situation and the current pandemic atmosphere is to create frozen products and with a digital-based marketing system. Meanwhile, for BUMDes Sialang Kubang, in managing the BUMDes, personal and institutional strengthening is needed in the form of Standard Operational Procedures (SOP) and the availability of an accurate and accountable information system.
\end{abstract}

Keywords: Business, Accounting, Tax, Digital, Marketing, SOP

\begin{abstract}
Abstrak
Setiap perguruan tinggi harus memiliki unit bisnis yang mampu mencari pendanaan selain dari mahasiswa. Salah satu perguruan tinggi yang memiliki unit bisnis adalah Institut Bisnis dan Teknologi Pelita Indonesia. Unit bisnis yang dijalankan yaitu Kantor Konsultan Bisnis, Akuntansi dan Pajak dengan jasa yang ditawarkan yaitu konsultasi bisnis, akuntansi dan keuangan serta perpajakan. Beberapa klien yang sudah ditangani oleh tim konsultan yaitu Rumah Makan Raso Stiujuah dan BUMDes Sialang Kubang. Metode yang dijalankan yaitu tim konsultan mencari akar setiap masalah yang dihadapi oleh klien, kemudian memberikan solusi yang terbaik bagi klien. Bagi Rumah Makan Raso Situjuah, untuk bertahan pada situasi dunia bisnis yang berubah dan suasana pandemi saat ini adalah menciptakan produk frozen dan dengan sistem pemasaran berbasis digital. Sedangkan bagi BUMDes Sialang Kubang, dalam mengelola BUMDes tersebut sangat diperlukan penguatan personal dan kelembagaan berupa Standar Operational Proocedure (SOP) serta tersedianya sistem informasi yang akurat dan akuntabel.
\end{abstract}

Kata kunci: Bisnis, Akuntansi, Pajak, Digital, Marketing, SOP

\section{PENDAHULUAN}

Saat ini lingkungan dunia bisnis berubah dengan sangat cepat yang menyebabkan semakin ketatnya persaingan dalam memasarkan produk atau jasa serta semakin pendeknya siklus hidup produk akibat kebutuhan konsumen yang berubah dengan cepat. Keadaan semakin dipersulit dengan adanya peraturan-peraturan baru dari pejabat atau lembaga pelayananan publik, yang mana peraturan-peraturan tersebut juga dapat berubah sewaktu-waktu, seperti salah satunya adalah peraturan perpajakan. Dengan semua kondisi tersbut, tentu saja dapat menyulitkan perusahaan dalam menjalankan usahanya. Akibatnya banyak dari mereka yang terpaksa gulung tikar atau tutup, yang ditandai dengan semakin menurunnya jumlah perusahaan di kota Pekanbaru. Dari data badan pusat statistik (BPS) kota Pekanbaru diketahui bahwa jumlah perusahaan di kota Pekanbaru terus mengalami penurunan yang semula berjumlah 2.354 unit pada tahun 2013, menjadi sejumlah 1.500 unit pada tahun 2017.

Kondisi ini tentu saja sangat mengkhawatirkan ditengah usaha pemerintah dalam meningkatkan jumlah wirausaha di Indonesia, dan tentu saja perlu dicarikan solusinya. Untuk itu muncullah gagasan dari civitas akademika STIE Pelita Indonesia (saat ini menjadi Institut Bisnis dan Teknologi Pelita Indonesia) untuk turut membantu memberikan solusi bagi para pelaku usaha di Kota Pekanbaru dengan mendirikan satu unit bisnis yaitu Kantor Konsultan Bisnis, Akuntansi dan Pajak dengan motto One Stop Business Solution Center (OSBSC). Kantor Konsultan 
Bisnis, Akuntansi dan Pajak telah didirikan pada tahun 2018 dengan dasar hukum pendirian adalah Surat Keputusan Ketua STIE Pelita Indonesia Nomor 016/II/SK/STIE-PI/610/2018 pada tanggal 26 Februari 2018. Kantor konsultan ini merupakan satu-satunya unit bisnis yang diwujudkan oleh Institut Bisnis dan Teknologi Pelita Indonesia.

Adapun bidang-bidang yang ditangani oleh Kantor Konsultan Bisnis, Akuntansi dan Pajak STIE Pelita Indonesia yaitu:

Tabel 1. Spesifikasi Jasa yang Ditawarkan

\begin{tabular}{|c|c|c|}
\hline No. & Bidang Jasa & Spesifikasi Jasa \\
\hline 1. & Manajemen & $\begin{array}{l}\text { a. Perbaikan pada sistem produksi/operasi perusahaan } \\
\text { b. Perbaikan pada sistem purchasing dan inventory } \\
\text { c. Perbaikan pada sistem pemeliharaan fasilitas } \\
\text { d. Perbaikan pada sistem rekrutmen, pelatihan, penempatan, } \\
\text { promosi dan pengupahan }\end{array}$ \\
\hline 2. & Akuntansi \& Keuangan & $\begin{array}{l}\text { a. Pembukuan atau bookkeeping } \\
\text { b. Pembuatan laporan keuangan } \\
\text { c. Analisa laporan keuangan } \\
\text { d. Payroll outsourcing } \\
\text { e. Transformasi sistem akuntansi } \\
\text { f. Akuntansi statutori } \\
\text { g. Audit internal } \\
\text { h. Audit inventory }\end{array}$ \\
\hline 3. & Perpajakan & $\begin{array}{l}\text { a. Perencanaan perpajakan } \\
\text { b. Pengisian SPT perpajakan } \\
\text { c. Pendampingan pemeriksaan perpajakan } \\
\text { d. Penanganan kasus perpajakan } \\
\text { e. Review perpajakan }\end{array}$ \\
\hline 4. & Pemasaran & $\begin{array}{l}\text { a. Pengembangan Merek } \\
\text { b. Efektivitas Aktivitas Promosi } \\
\text { c. Riset Pasar } \\
\text { d. Ekspansi dan Perluasan Pasar } \\
\text { e. Pelatihan \& motivasi tenaga penjual }\end{array}$ \\
\hline 5. & Inovasi & $\begin{array}{l}\text { a. Reseacrh dan Development } \\
\text { b. Pengembangan Produk/Jasa } \\
\text { c. Desain Produk/Jasa Baru }\end{array}$ \\
\hline 6. & $\begin{array}{l}\text { Studi kelayakan bisnis } \\
\text { dan kewirausahaan }\end{array}$ & $\begin{array}{l}\text { a. Analisis kelayakan produk } \\
\text { b. Analisis kelayakan industri dan pasar } \\
\text { c. Analisis kelayakan organisasi } \\
\text { d. Analisis kelayakan keuangan }\end{array}$ \\
\hline
\end{tabular}

Beberapa klien yang ditangani oleh Kantor Konsultan yaitu Rumah Makan Raso Situjuah Pekanbaru dan Badan Usaha Milik Desa (BUMDes) Sialang Kubang Kampar. Permasalahan yang terdapat pada Rumah Makan Raso Situjuah Pekanbaru adalah menurunnya tingkat penjualan makanan akibat pandemi Covid-19. Sedangkan permasalahan yang terdapat pada BUMDes Sialang Kubang adalah kurangnya pengetahuan pengurus pada manajemen tata kelola.

\section{METODE}

Kegiatan pengabdian ini dimulai dengan sosialisasi dan audiensi oleh tim konsultan ke berbagai pelaku usaha. Bagi pelaku usaha yang bersedia menjadi klien, tim konsultan akan mencari akar permasalahan dan melakukan diskusi dengan tim konsultan untuk mencarikan 
solusi yang tepat bagi klien tersebut. Dalam menyelesaikan permasalahan klien, Kantor Konsultan Bisnis, Akuntansi dan Pajak memberikan metode penyelesaian sebagai berikut:

1. Rumah Makan Raso Situjuah

Permasalahan yang dihadapi yaitu terjadinya penurunan penjualan makanan akibat pandemi Covid-19. Metode penyelesaian yang diberikan oleh tim konsultan yaitu:

a. Menyiapkan Produk Frozen

Produk frozen adalah olahan makanan yang tahan lama dan mudah dalam penyajiannya (Santoso et al., 2018). Produk frozen dilakukan dengan cara menurunkan temperatur makanan tersebut sampai dibawah titik beku es, sehingga akan menghambat pertumbuhan mikroorganisme dan aktivitas enzim di dalam makanan tersebut. Akibatnya, makanan akan menjadi lebih awet dan tidak mudah membusuk (Sasongko et al., 2016).

\section{b. Menyiapkan Sistem Digital Marketing untuk Produk Frozen}

Pemasaran (marketing) merupakan proses sosial manajerial yang di dalamnya terdapat individu atau kelompok untuk mendapatkan apa yang mereka butuhkan dengan cara menciptakan, menawarkan dan mempertukarkan produk yang bernilai dengan pihak lain (Diniaty \& Agusrinal, 2014). Pada era Revolusi Industri 4.0 ini, mau tidak mau seluruh aktifitas harus mengarah kepada penggunaan teknologi informasi, salah satunya adalah digital maketing. Digital marketing merupakan pemanfaatan media seperti televisi, radio, perangkat mobile hingga internet, dimana media tersebut akan memberikan infografis tentang berbagai produk yang dipasarkan perusahaan, terutama penekanan merek sebuah barang atau jasa (Oktaviani \& Rustandi, 2018).

Dari beberapa perangkat yang paling populer saat ini sebagai sarana digital marketing adalah media sosial. Menurut Soeparno \& Sandra (2011) media sosial merupakan sebuah revolusi besar yang mampu mengubah perilaku manusia dimana relasi pertemanan dilakukan melalui digital dan dioperasikan melalui situs-situs jejaring sosial. Dari hasil penelitian yang dilakukan oleh Purbohastuti (2017) menunjukkan bahwa media promosi yang paling efektif adalah media sosial, hal ini dikarenakan media sosial sangat mudah diakses oleh semua orang dimana saja dan kapan saja karena handphone selalu dibawa kemana-mana dan setiap informasi selalu up to date.

\section{BUMDes Sialang Kubang}

Permasalahan yang dihadapi oleh BUMDes Sialang Kubang yaitu kurangnya pengetahuan pengurus dalam manajemen tata kelola. Metode penyelesaian yang diberikan oleh tim konsultan yaitu:

\section{a. Menyiapkan Standar Operational Procedure (SOP)}

Salah satu cara untuk mewujudkan penyelenggaraan BUMDes yang baik adalah penguatan personal dan kelembagaan (Adam et al., 2020). Penguatan personal dan kelembagaan ini dapat dilakukan dengan cara adanya standarisasi pekerjaan yang dilakukan oleh pengurus dan karyawan yaitu dengan adanya Standar Operational Procedure (SOP). SOP adalah suatu perangkat yang mengatur tahapan suatu proses kerja atau prosedur kerja tertentu (Budihardjo, 2014). Menurut Gabriele (2018) adanya SOP menjadi pedoman kepada karyawan dalam melakukan tugasnya dan untuk meminimalisasi kesalahan saat melakukan tugas masing-masing karyawan. Menurut Winata (2016) sebuah SOP dibuat sebagai pedoman sehingga menghasilkan prosedur yang sama dan dapat menghasilkan produk yang sesuai dengan standarisasi yang ditetapkan.

b. Penggunaan Aplikasi Desaku 
Setiap kegiatan usaha harus memiliki sebuah sistem informasi yang akurat, tepat dan akuntabel. Begitu juga dalam mengelola sebuah BUMDes, sistem informasi pada BUMDes menjadi hal yang sangat penting. Begitu juga pada BUMDes Sialang Kubang, tim konsultan menyarankan agar menggunakan sebuah sistem informasi sehingga setiap informasiinformasi yang dibutuhkan dapat diperoleh dengan cepat. Sistem informasi yang yang ditawarkan yaitu aplikasi Desaku. Aplikasi Desaku merupakan aplikasi yang diciptakan oleh tim konsultan bekerjasama dengan perusahaan IT. Aplikasi Desaku terintegrasi dengan seluruh unit BUMDes, sehingga ketika ingin melihat kinerja BUMDes maka kinerja seluruh unit bisnis juga akan terlihat.

\section{HASIL DAN PEMBAHASAN}

Dari permasalahan 2 (dua) klien yang ditangani oleh tim konsultan, maka solusi yang diberikan untuk masing-masing klien adalah sebagai berikut:

1. Rumah Makan Raso Situjuah

a. Menyiapkan produk frozen

Dengan adanya kebijakan Pembatasan Sosial Berskala Besar (PSBB) akibat pandemi Covid19 di Pekanbaru pada tanggal 17 April sampai tanggal 14 Mei 2020, menyebabkan banyak pelaku-pelaku usaha khususnya dibidang kuliner menghentikan kegiatan usahanya, termasuk salah satunya adalah Rumah Makan Raso Situjuah. Untuk menyiasati agar tidak berdampak terlalu lama, maka dilakukan produksi makanan beku (frozen food). Tim konsultan merekomendasikan kepada pimpinan rumah makan untuk membuat produk frozen terhadap produk yang paling laris, seperti ayam ungkep, dendeng bakar, iga bakar dan sambalado hijau.
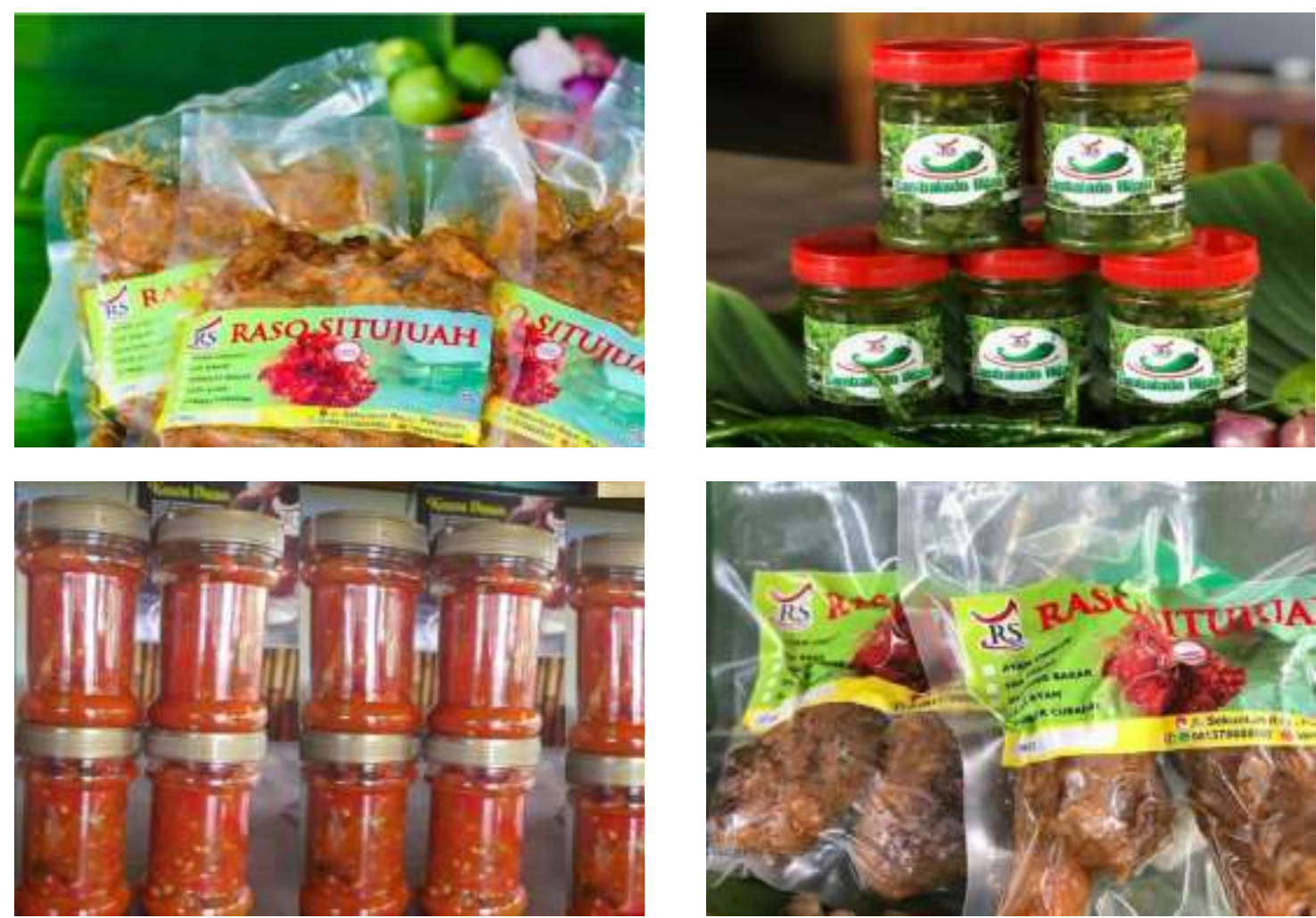

Gambar 1. Produk Frozen Rumah Makan Raso Situjuah 
b. Menyiapkan sistem digital marketing produk frozen

Sistem digital marketing yang dipersiapkan sebagai langkah awal yaitu dengan menggunakan media sosial. Hal ini dikarenakan media sosial merupakan media yang tidak asing lagi bagi setiap orang. Bahkan setiap kebutuhan yang kita perlukan juga ditersedia di media sosial.

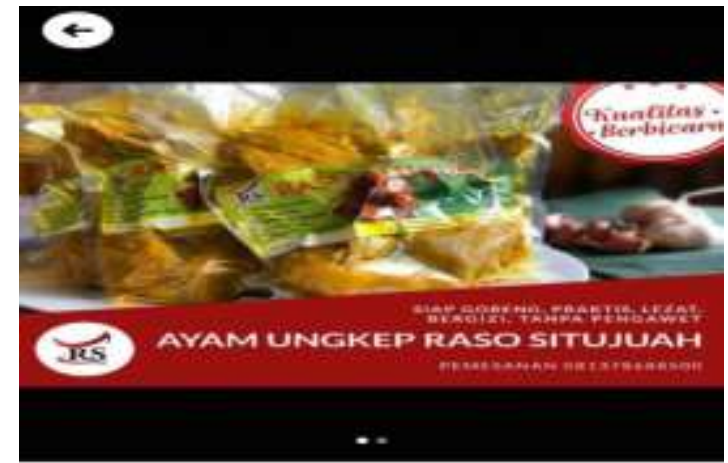

Raso situjuah

Kirim Pesan ke penjual untuk

merianyakan harga

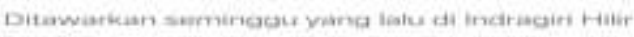

o kirim pesan ke perival

(a)

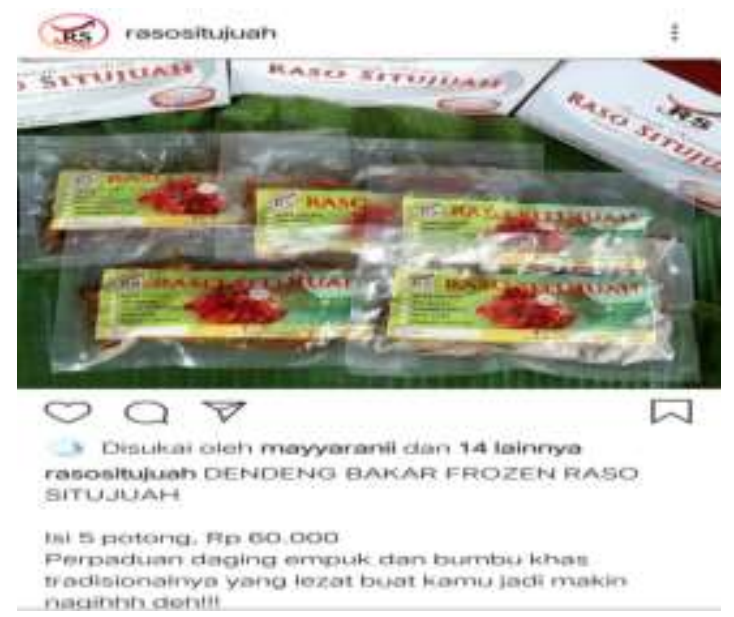

(b)

Gambar 2. Iklan di Marketplace Facebook (a) dan Instagram (b)

2. BUMDes Sialang Kubang

a. Menyiapkan Standar Operational Procedure (SOP)

SOP yang diberikan oleh tim konsultan yaitu SOP Pengelolaan, SOP Simpan Pinjam dan SOP Inventory. SOP Pengelolaan berkaitan dengan tugas pokok dan fungsi pengelola BUMDes. SOP Simpan Pinjam berisi uraian prosedur pemberian pinjaman dan penagihan. Sedangkan SOP Inventory berisi tentang prosedur barang masuk dan barang keluar untuk unit usaha kredit barang.
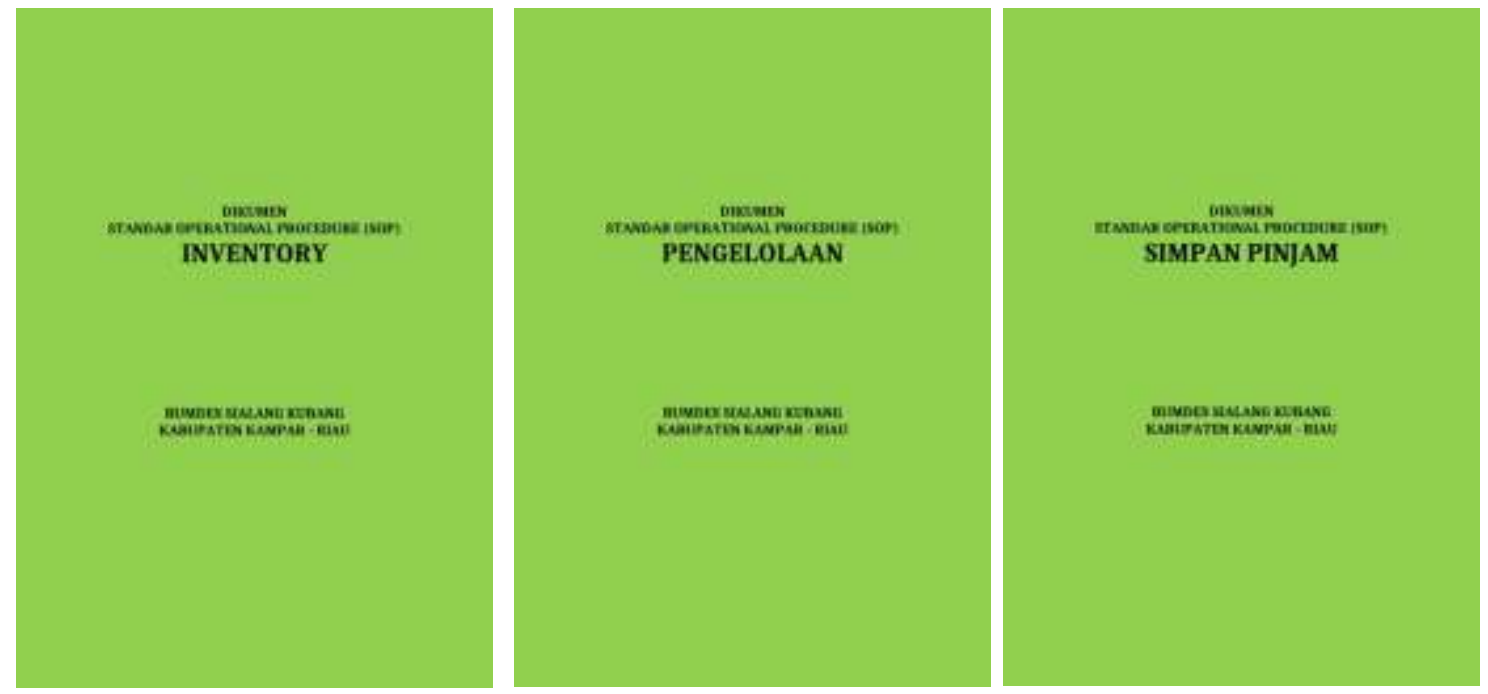

Gambar 3. Berbagai Dokumen SOP BUMDes Sialang Kubang 
b. Penggunaan Aplikasi Desaku

Aplikasi Desaku bertujuan untuk menyiapkan sistem informasi bagi pengurus BUMDes dan stakeholder lainnya. Aplikasi ini terintegrasi dengan seluruh unit bisnis BUMDes. Sehingga dengan adanya aplikasi ini menghindari tingkat kecurangan dan menyediakan informasi terkait kinerja BUMDes dengan cepat, akurat dan akuntabel.
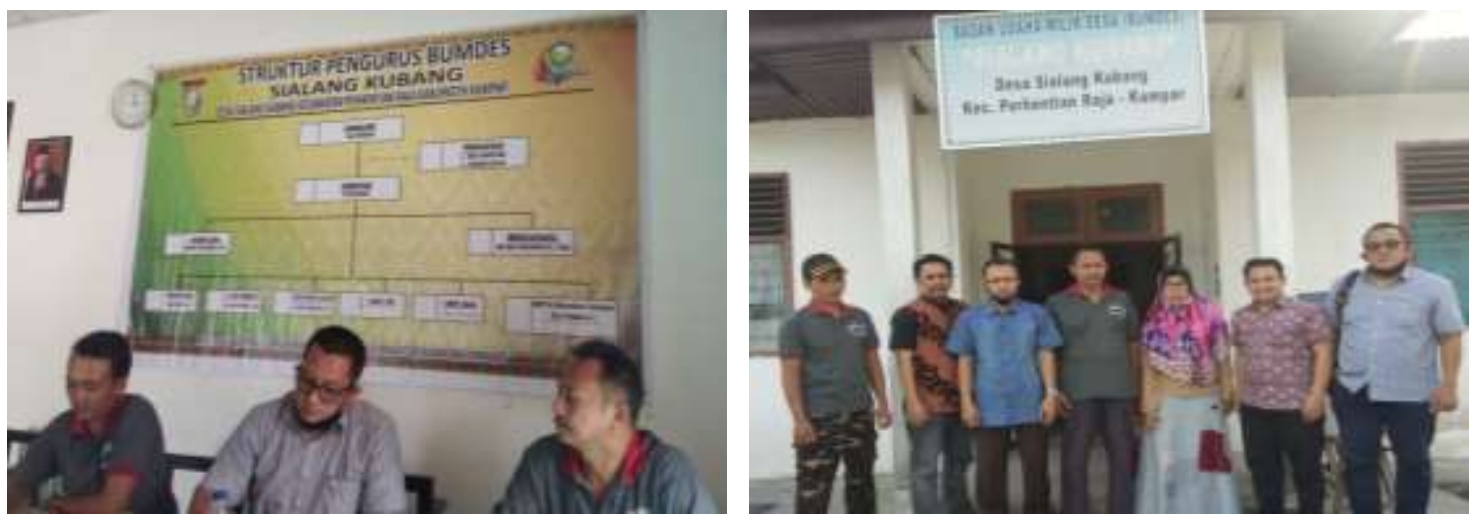

Gambar 4. Penjelasan SOP dan Penggunaan Aplikasi Desaku di BUMDes Sialang Kubang

\section{KESIMPULAN}

Dari uraian pada hasil dan pembahasan di atas, maka dapat disimpulkan:

1. Untuk menghadapi dunia bisnis yang berubah dan tidak menentu, apalagi suasana pandemi Covid-19 saat ini, setiap pelaku usaha harus memiliki konsep bisnis dan produk yang mampu bersaing. Apalagi bisnis kuliner, sangat berdampak sekali karena aktifitas manusia dibatasi. Untuk itu, salah satu alternatif yaitu menciptakan produk frozen dan pemasaran dengan sistem digital marketing.

2. Dalam mengelola sebuah badan usaha penguatan personal dan kelembagaan sangat penting untuk dilakukan. Hal ini berkaitan dengan bagaimana sumber daya manusia yang ada mampu bekerja dengan tugas pokok dan fungsi yang disiapkan, salah satunya adalah SOP. Keberadaan SOP bertujuan untuk standarisasi pekerjaan bagi setiap karyawan. Selain itu, ketersediaan sistem informasi juga sangat penting. Karena dengan adanya sistem informasi akan mengurangi kecurangan dan setiap informasi dapat dihasilkan dengan cepat, akurat dan akuntabel.

\section{UCAPAN TERIMA KASIH}

Ucapan terima kasih yang sebesar-besarnya penulis sampaikan kepada:

1. Kementerian Riset dan Teknologi/Badan Riset dan Inovasi Nasional, yang telah memberikan pendanaan pengabdian kepada masyarakat dalam skema Program Pengembangan Usaha Produk Pengembangan Inteletual Kampus (PPUPIK).

2. Fakultas Bisnis Institut Bisnis dan Teknologi Pelita Indonesia, yang telah memberikan dana pendamping dalam kegiatan pengabdian kepada masyarakat skema PPUPIK ini. 


\section{DAFTAR PUSTAKA}

Adam, H., Ristawati, R., Ramadhanti, S., \& Nugraha, X. (2020). Pembentukan Badan Usaha Milik Desa di Sumberanyar Pasuruan untuk Peningkatan Kesejahteraan Masyarakat. Dinamisia: Jurnal Pengabdian Kepada Masyarakat, 4(2), 293-299.

Budihardjo, M. (2014). Panduan Praktis Menyusun SOP. Jakarta: Raih Asa Sukses.

Diniaty, D., \& Agusrinal. (2014). Perancangan Strategi Pemasaran pada Produk Anyaman Pandan. Jurnal Sains, Teknologi dan Industri, 11(2), 175-184.

Gabriele. (2018). Analisis Penerapan Standar Operasional Prosedur (SOP) di Departemen Marketing dan HRD PT Cahaya Indo Persada. Agora, 6(1).

Oktaviani, F., \& Rustandi, D. (2018). Implementasi Digital Marketing dalam Membangun Brand Awarenss. Profesi Humas, 3(1), 1-20.

Purbohastuti, A. W. (2017). Efektivitas Media Sosial sebagai Media Promosi. Tirtayasa Ekonomika, 12(2), 212-231.

Santoso, I., Mustaniroh, S. A., \& Pranowo, D. (2018). Keakraban Produk dan Minat Beli Frozen Food: Peran Pengetahuan Produk, Kemasan, dan Lingkungan Sosial. Jurnal Ilmu Keluarga dan Konsumen, 11(2), 133-144.

Sasongko, P., Yuniningsih, S., \& Yasak, E. M. (2016). Aplikasi Frozen Food Technology untuk Menurunkan Tingkat Kerugian Produk pada Kelompok Perempuan Buta Aksara Alfabet Desa Nogosari Kecamatan Rowokangkung Kabupaten Lumajang Jawa Timur. Jurnal Akses Pengabdian Indonesia, 1(1), 8-17.

Soeparno K., \& Sandra, L. (2011). Social Psychology: The Passion of Psychology. Buletin Psikologi, 19(1), 16-28.

Winata, S. V. (2016). Perancangan Standard Operating Procedure (SOP) pada Chocolab. Performa: Jurnal Manajemen dan Start-Up Bisnis, 1(1), 77-86. 